\title{
Article \\ Relationship Between Obesity And Parasympathetic Nerve Function
}

\author{
Shahin Akhter ${ }^{1}$,Noorzahan Begum ${ }^{2}$, Sultana Ferdousi ${ }^{3}$, Shelina Begum ${ }^{4}$, Taskina Ali $^{5}$
}

Back ground: Obesity is a potential risk factor for cardiovascular morbidity and mortality. As certain cardiovascular disorders associated with autonomic nerve which dysfunction often coexist in obese persons, investigations of autonomic nerve function especially parasympathetic nerve function in obese, for detection of early autonomic impairment can be potentially important to prevent complications. Objective: The present study was done to observe the parasympathetic nerve function status in obese persons in order to investigate the relationship of autonomic nerve function with obesity. Study design: This study was conducted in the department of Physiology of Bangabandhu Sheikh Mujib Medical University, Dhaka, Bangladesh during July 2006-June 2007. For these 40 apparently healthy obese subjects of both sexes with BMI $\geq 25 \mathrm{~kg} / \mathrm{sqm}$. were included in study group. Age and sex matched 40 apparently healthy non obese subjects with BMI range 18.5-22.9 kg/ sqm. were taken as control for comparison. Methods: To assess parasympathetic nerve function status, heart rate response to valsalva(valsalva ratio), heart rate response to deep breathing and heart rate response to standing ( $30^{\text {th }}: 15^{\text {th }}$ ratio) were determined by 3 noninvasive cardiovascular reflex tests . Data were collected by recording ECG of all subjects under test condition. The correlations of these parasympathetic nerve function parameters with BMI were also studied. Unpaired Student' $t$ ' test and Pearson correlation coefficient test were used for statistical analysis. Results: Valsalva ratio (1.47 \pm 0.24 vs $1.67 \pm 0.31)$, HR response to deep breathing (19.62 \pm 5.55 vs $27.59 \pm 6.51)$ and HR response to standing $(1.07 \pm 0.07$ vs $1.13 \pm 0.018)$ were significantly decreased in obese subjects than those of non obese control. All these parameters were negatively correlated with BMI. and these relatioship were statistically significant. Conclusion: The results of this study indicate that parasympathetic nerve function may be reduced in apparently healthy obese subjects.

Key words: Obesity; valsalva; parasympathetic; deep breathing.

J Bangladesh Soc Physiol.2008 Dec;(3):50-54.

For author affiliations, see end of text.

http://www.banglajol.info/index.php/JBSP

\section{Introduction:}

$\mathbf{O}$ besity is a nutritional health problem which is gradually rising and affecting a major section of adult population'. Obese people have greater risk of developing both cardiovascular and metabolic diseases like hypertension, atherosclerosis, diabetes mellitus and gallbladder diseases ${ }^{2}$. In the mid 1990s WHO expressed concern to the growing obesity epidemic throughout the world ${ }^{1}$. In 2005, WHO reported that globally, approximately 1.6 billion adults (age15+) were overweight and at least 400 million adults were obese. Overweight population will reach approximately to 2.3 billion and obese population to 700 million by $2015^{3}$.

Obesity is a condition of excess fat deposition in the body ${ }^{4}$. Body mass index (BMI) is commonly used to identify and classify overweight and obesity in adult individuals ${ }^{4}$.

J Bangladesh Soc Physiol. 2008 Dec;(3):50-54 
According to WHO standards, overweight and obesity are indicated by BMI $>25$ and $>30$ respectively. But for Asians, the cut off point for overweight (23 to 24.9) and obese 25 are lower than the WHO standard ${ }^{5}$.

Obesity usually results from an imbalance between energy intake and energy expenditure which is under a feedback regulation involving a complex interaction among endocrine, nervous, metabolic and psychological factors ${ }^{6}$. Hypothalamus plays an important role in the regulation of body weight ${ }^{2}$. The importance of hypothalamus and autonomic nerve activity for maintaining energy storage is supported by some experimental observations from animal model study $^{7}$. More studies on autonomic nervous activity in human obese persons have reported controversial findings; These include hypoactivity of parasympathetic and associated hyperactivity of sympathetic nerve function ${ }^{8}$; both reduced sympathetic and parasympathetic nerve activity ${ }^{9-10}$ and increased parasympathetic activity with a decreased sympathetic nerve activity ${ }^{7}$. Sometimes, obesity is associated with minor impairments of autonomic nerve function and in most of the cases, changes were found in parasympathetic division of autonomic nervous system which is analogous to the early stage of autonomic neuropathy in diabetes mellitus ${ }^{\mathbf{1 1}}$.

Obesity related health problems including various cardiovascular and metabolic diseases are not uncommon in our community. In addition to recognized complications of obesity, autonomic nerve dysfunction may also coexist with certain cardiovascular disorders in obese person. In obese persons, investigations of autonomic nerve functions especially parasympathetic one can be potentially important for detection of early autonomic nerve function impairment which there by may be helpful to prevent its complications. But no published data on parasympathetic nerve function status in obese people is available in Bangladesh. Therefore, this study was aimed to observe the parasympathetic nerve function status in obese subjects and also to find out any relationship between parasympathetic nerve activity and obesity.

\section{Methods:}

This cross sectional study was conducted in department of Physiology of Bangabandhu Sheikh Mujib Medical University, Dhaka, Bangladesh. For this, 80 apparently healthy subjects of both sexes with age range from 18-40 years were selected from the different areas of Dhaka city.

On the basis of their body mass index, all the subjects were divided into two groups. Group A(control) consisted of 40 nonobese subjects with BMI between 18.50 - $22.90 \mathrm{~kg} / \mathrm{sqm}$. Group B (study)consisted of obese subjects with BMI $\geq 25 \mathrm{~kg} / \mathrm{sqm}$.. The subjects with age $>40$ years, overweight (BMI 23 - $24.9 \mathrm{~kg} / \mathrm{sqm}$.), diabetes mellitus, chronic renal failure, suffering from any obvious cardiovascular diseases, chronic obstructive lung diseases, previous history of head injury and smokers were excluded from this study.

The purpose and expected outcome of the study were explained to each subject. They were encouraged for voluntary participation. Written informed consent was obtained from each subject. Detailed medical and family history was taken and thorough clinical examination was done. All information were recorded in a preformed questionnaire. Height and weight of the subjects were recorded and BMI was calculated. Random blood sample was collected to determine blood glucose and serum creatinine to exclude diabetes mellitus and chronic renal failure. Blood glucose and serum creatinine level were measured by auto analyzer in the hematology laboratory of the Physiology department. Then the autonomic nerve function parameters like valsava ratio, heart rate response to deep breathing and heart rate response to standing ( $30^{\text {th }}: 15^{\text {th }}$ ratio) were determined by performing valsalva maneuver, deep breathing and orthostatic test using an ECG machine and a 


\section{Article}

mercury column attached to a mouthpiece by a rubber tube.

Each of the subject was briefed about the procedure in detail and encouraged to obtain maximum efficient performance. Cardiovascular reflex tests were conducted in the neurophysiology laboratory from 9.00am$2.30 \mathrm{pm}$ in a comfortable environment. The subjects were allowed to rest and relax for at least 10 minutes upon arrival. In all subjects, valsalva maneuver, deep breathing and orthostatic test ( $30^{\text {th }}: 15^{\text {th }}$ ratio) were performed sequentially. Before the tests, all the subjects took rest in supine position in a bed for a minimum of 10 minutes and then their basal heart rate was recorded. Results were compared between the groups. Relationship of all the parameters with BMI were observed.

Data were entered in computerized SPSS program version-12. All the data were expressed as mean \pm SD (Standard deviation). Statistical analysis were done by unpaired Student's ' $t$ ' test and Pearson's correlation-coefficient test as applicable.

\section{Results:}

Anthropometric details of the subjects are given in table-I.

Both groups are matched for age and sex. Mean weight and BMI were significantly higher $(p<0.001)$ in obese subjects compared to that of nonobese control subjects. All the parasympathetic nerve function parameters were analyzed separately in male and female. But no significant differences were observed between male and female.

The results of the parasympathetic nerve function tests are shown in table-II.

Obese subjects(Group B) had significantly lower valsalva ratio, HR response to deep breathing and $30^{\text {th }}: 15^{\text {th }}$ than those of control(group A).

The results of correlations are presented in figure 1,2,3.

All the parasympathetic nerve function parameters showed statistically significant negative correlation with BMI.
Parasympathetic Nerve Function and Obesity

Table-I

Mean $\pm S D$, Age, height, weight and body

mass index in the study groups $(n=80)$

\begin{tabular}{lcc}
\hline Parameters & $\begin{array}{c}\text { Group-A } \\
(\mathrm{n}=40)\end{array}$ & $\begin{array}{c}\text { Group-B } \\
(\mathrm{n}=40)\end{array}$ \\
\hline Age(years) & $31.02 \pm 5.04$ & $31.77 \pm 4.66^{\mathrm{ns}}$ \\
& $(20-40)$ & $(19-40)$ \\
Height(cm) & $165.02 \pm 7.64$ & $163.37 \pm 8.69^{\mathrm{ns}}$ \\
& $(154-180)$ & $(152-180)$ \\
Weight $(\mathrm{kg})$ & $57.6 \pm 6.49$ & $76.05 \pm 9.18^{* * *}$ \\
& $(48-72)$ & $(58-98)$ \\
BMI $\left(\mathrm{kg} / \mathrm{m}^{2}\right)$ & $21.44 \pm 1.24$ & $28.45 \pm 1.78^{* * *}$ \\
& $(18.75-22.90)$ & $(26.17-33.96)$ \\
\hline
\end{tabular}

Group A : Nonobese subjects having BMI between 18.50 to $22.90 \mathrm{~kg} / \mathrm{m}^{2}$

Group B : Obese subjects having BMI $>25 \mathrm{~kg} / \mathrm{m}^{2}$ Values in parenthesis indicate range. $\mathrm{n}=$ total number of subjects.ns $=$ not significant.

$* * *=$ significant at $<0.001$ level.

Table-II

Parasympathetic nerve function parameters in the study groups $(n=80)$

\begin{tabular}{lcc}
\hline Parameters & $\begin{array}{c}\text { Group-A } \\
\mathrm{n}=40\end{array}$ & $\begin{array}{c}\text { Group-B } \\
\mathrm{n}=40\end{array}$ \\
\hline Valsalva ratio & $1.67 \pm 0.31$ & $1.47 \pm 0.24^{* *}$ \\
& $(1.21-2.34)$ & $(1.07-1.98)$ \\
& $27.57 \pm 6.51$ & $19.62 \pm 5.55^{* * *}$ \\
Heart rate response & $(16.18-39.83)$ & $(9.28-31.89)$ \\
to deep breathing & & \\
(beats/min) & & \\
$\begin{array}{l}\text { Heart rate response } \\
\text { to standing }\end{array}$ & $(1.13 \pm 0.08$ & $1.07 \pm 0.07^{* *}$ \\
(30 ${ }^{\text {th }}$ :15 & & $(0.9-1.25)$ \\
\hline
\end{tabular}

Group A : Nonobese subjects having BMI between 18.50 to $22.90 \mathrm{~kg} / \mathrm{m}^{2}$

Group B : Obese subjects having BMI $\geq 25 \mathrm{~kg} / \mathrm{m}^{2}$ Values in parenthesis indicate range.

$\mathrm{n}=$ total number of subjects. $* *=$ significant at $<0.01$

level. $* * *=$ significant at $<0.001$ level.

J Bangladesh Soc Physiol. 2008 Dec;(3):50-54 
Parasympathetic Nerve Function and Obesity

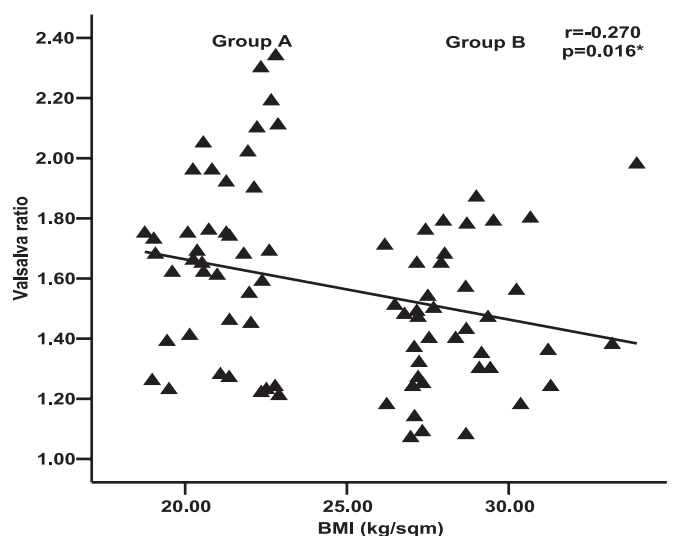

Figure 1: Relationship between BMI and valsalva ratio in the obese groups $(n=80)$

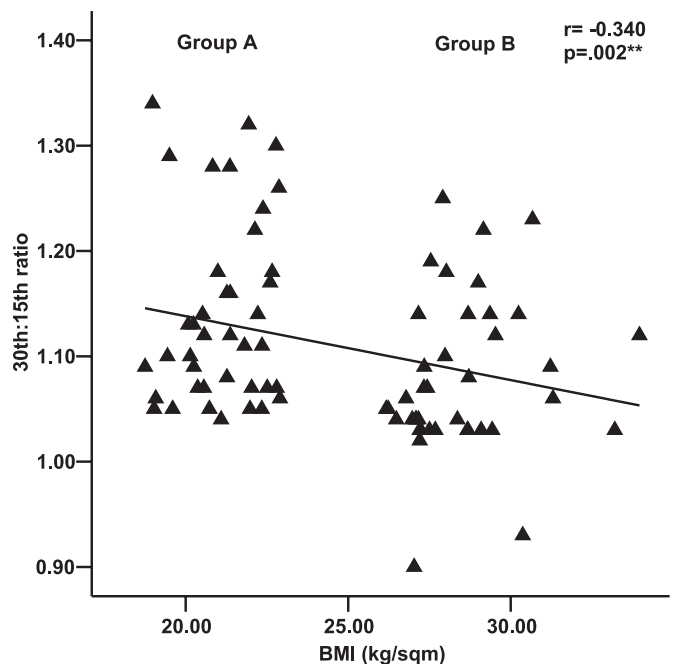

Figure 3: Relationship between BMI and $30^{\text {th }}: 15^{\text {th }}$ ratio in the obese groups $(n=80)$

\section{Discussion:}

The results in the present study have shown that HR response to valsalva maneuver, to deep breathing and standing were significantly lower in obese subjects than in non obese control Which is similar to the findings observed by some other investigators of different countries ${ }^{12-15}$. But relatively higher valsalalva ratio and lower deep breathing and standing test in obese subject compared to control subjects but not statistically significant were also found by some other group
Article

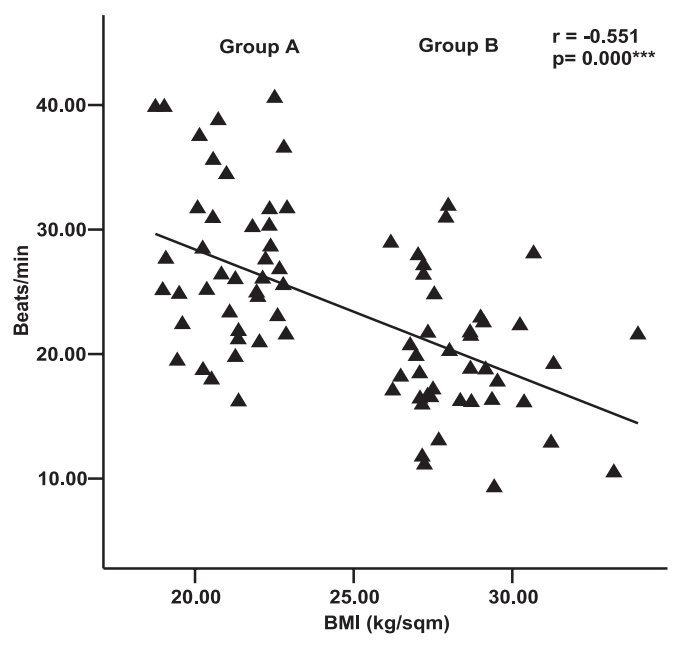

Figure 2: Relationship between BMI and HR response to deep breathing in the obese groups $(\mathrm{n}=80)$

of observers ${ }^{6}$. In this study, all the parasympathetic nerve function parameters showed negative correlation with BMI and it was statistically significant. Therefore, the present study has shown that parasympathetic nerve dysfunction may occur in obese people. However,the exact mechanism that may cause impairment of parasympathetic nerve function has not yet been clearly established. Some researchers suggested that gradual development of insulin resistance in target tissues with the beginning of excess weight gain in obesity is responsible for subsequent development of hyperinsulinaemia ${ }^{4}$. This hyperinsulinaemia has got a role in low cardiac vagal activity in obese person ${ }^{\mathbf{1 6}}$. Though the relationship between insulin resistance and parasympathetic dysfunction is not clear, but several researchers made various suggestions such as high insulin level or insulin resistance may cause damage to autonomic nerves at any level of their reflex arc ${ }^{17}$, insulin resistance may cause a deterioration of microcirculation in many tissues including nerves which may lead to neural ischemia ${ }^{\mathbf{1 7}}$ and thereby damage of cardiac parasympathetic nerve terminals occur at the level of cardiac muscle or vascular wall ${ }^{18}$. 


\section{Article}

Therefore, this study concludes that obesity may reduce parasympathetic nerve function.

\section{Authors Affiliations:}

*1. Shahin Akhtar,Lecturer, Physiology, Chittagong Medical College, Chittagong Bangladesh.

2. NoorzahanBegum, Professor and Chairman, Department of Physiology, BSMMU. Email:noorzahanbeg@ yahoo.com

3. Sultana Ferdousi,Assistant Professor, Department of Physiology, BSMMU.Email:sferdousiratna @yahoo.com

4. Shelina Begum, Professor, Department of Physiology, BSMMU.

5. Taskina Ali, Assistant Professor, Department of Physiology, BSMMU. Email:taskinadr @gmail.com

*For correspondance

\section{References:}

1. Weisell RC. Body mass index as an indicator of obesity. Asia Pacific J Clin Nutr. 2002; 11:S681-S684

2. Ganong WF. Review of Medical Phisiology. $22^{\text {nd }}$ ed. USA: Mc Graw- Hill Company; 2005.

3. Guyton AC, Hall JE. Text book of medical physiology. $11^{\text {th }}$ ed. Singapore: W.B.Saunders; 2006.

4. Steering Committee. The Asia-Pacific perspective: Redefining obesity and its treatment. Melbourne: International Diabetes Institute, 2000.

5. Colak R, Donder E, Karaoglu A, Ayhan O, Yalniz A. Obesity and the activity of autonomic nervous system. Turk J Med Sci. 2000; 30: 173-176.

6. Bray GA. Auotonomic and endocrine balance in the regulation of energy balance. Fed Proc. 1986; 45: 1404-1410.

7 Arrone LJ, Mackintosh R, Rosenbaum M, Liebel RL, Hirsch J. Autonomic nervous system activity in weight gain and weight loss. Am J Physiol. 1995; 269: R222R225.

8. Hofmann KL, Mussgay L, and Ruddel H. Autonomic cardiovascular regulation in obesity. J Endocrinol. 2000;164: 59-66.
Parasympathetic Nerve Function and Obesity

19. Peterson HR, Rothschild M, Weingberg CR, Fell RD, Meleish KR, Pfeifer MA. Body fat and the activity of autonomic nervous system. N Eng J Med. 1988; 28:1077-1083.

10. Mathias CJ and Bannister R. Autonomic failure. A textbook of clinical disorders of the autonomic nervous system. $3^{\text {rd }}$ ed. Newyork: Oxford University Press; 1992.

11. Rossi M, Marti G, Ricordi L, Fornasari G, Finardi G, Fratino P, and Bernardi

L. Cardiac autonomic dysfunction in obese subjects. Clin Sci. 1989; 76: 567-572.

12. V alensi P, Bich Ngoc PT, Idriss S, Paries J, Cazes P, Lormeau B and Attali JR. Haemodynamic response to an isometric exercise test in obese patients: Influence of autonomic dysfunction. Int J obes. 1999; 23:543-549.

13. Emdin M, Gastaldelli A, Muscelli E, Macerata A, Natali A, Camastra S and Ferrannini E. Hyperinsulinemia and Autonomic Nervous System Dysfunction in Obesity: Effects of Weight Loss. Circulation. 2001; 103: 513-519.

14. Valensi P, Lormeau B, Dabbech M, Miossec P, Paries J, Dauchy F et al., Glucose induced thermogenesis, inhibition of lipid oxidation rate and autonomic dysfunction in non- diabetic obese women. Int J obes. 1998, 22:494-499.

15. Borne PVD, Hausberg M, Hoffman RP, Mark AL and Anderson EA. Hyperinsulinaemia produces cardiac vagal withdrawl and nonuniform sympathetic activation in normal subjects. Am J Physiol Regul Integr Comp Physiol. 1999; 276:178-183.

16. Valensi P, Paries J, Lormeau B, Attia S, Attali JR. Influence of nutrients on cardiac autonomic function in nondiabetic overweight subjects. Metabolism. 2005; 54: 1290-1296.

18. Valensi P, Nguyen TN, Idriss S, Cazes P, Karam G, Paries J, Miossec P and Attali JR. Influence of parasympathetic dysfunction and hyperinsulinaemia on the haemodynamic response to an isometric exercise in non insulin dependent diabetes mellitus. Metabolism. 1998; 47: 934-939. 